\title{
Treatment Outcomes of CT-guided High-dose 3-dimensional Conformal Radiotherapy for Localized Prostate Cancer
}

\author{
Tatsuyuki Abe ${ }^{1}$, Yukinori Okada ${ }^{1}$, Mio Shinozaki ${ }^{1}$, Hiromichi Gomi ${ }^{1}$, \\ Yasuo Nakajima ${ }^{1}$, and Tatsuya Chikaraishi ${ }^{2}$
}

(Received for Publication: August 4, 2015)

\begin{abstract}
Purpose: We studied the treatment outcomes of CT-guided 3-dimensional conformal radiotherapy (3DCRT) for localized prostate cancer using doses of 74-76 Gy.

Materials and Methods: In total, 139 patients with T1c to T3bN0M0 prostate cancer were enrolled between October 2007 and May 2014 in this retrospective study. The median patient age was 74 years (range, 56-81 years). There were 13 low-risk, 30 intermediate-risk, and 96 high-risk patients according to National Comprehensive Cancer Network definitions. Androgen deprivation therapy (ADT) was used in 123 patients (88\%), with a median treatment period of 25 months (range, 1-128 months). Biochemical relapse was evaluated according to the Phoenix definition, while adverse events were evaluated according to Common Terminology Criteria for Adverse Events (version 4.0). Median follow-up was 42 months (range, 13-94 months).

Results: Three-year biochemical relapse-free survival (bRFS) rates were 100\%, 100\%, and 92\%, respectively, for low-risk, intermediate-risk, and high-risk groups, while 3-year overall survival was $100 \%, 96 \%$, and 95\%, respectively. Meanwhile, 3-year distant metastasis-free survival was $100 \%, 100 \%$, and $96 \%$, and 3-year causespecific survival was $100 \%, 100 \%$, and $98 \%$. Multivariate analysis showed that long-term ADT (24 months or longer) was a factor influencing bRFS in the high-risk group (hazard ratio $0.23, \mathrm{p}=0.044$ ). Rates of grade 2 late rectal and urinary toxicities were $3.6 \%$ and $0.7 \%$ respectively, while no grade 3 or higher toxicities were observed.
\end{abstract}

Conclusion: These results demonstrate the safety of high-dose CT-guided 3DCRT performed at our hospital.

\section{Key words}

prostate cancer, image-guided radiotherapy, 3-dimensional conformal radiotherapy, androgen deprivation therapy, biochemical relapse-free survival

\section{Introduction}

The rate of detection of localized prostate cancer has increased due to the prevalence of prostate-specific antigen (PSA) testing. While external irradiation is standard radical therapy for localized prostate cancer, 72 Gy or higher doses of irradiation is required to achieve local control comparable to radical prostatectomy ${ }^{1)}$. Conventional external irradiation, which requires a sufficient margin from the target in consider- ation of physiological movement of prostate position, cannot be administered at doses higher than 70 Gy to avoid late injury. In recent years, image-guided radiotherapy (IGRT), which involves CT-based targeting and positional correction before irradiation to enhance accuracy, has been increasingly used, allowing dose escalation to 70 Gy or higher. Randomized studies have shown that high-dose external irradiation of 78 Gy or higher improves rates of biochemical control for prostate cancer $^{2-7)}$. Two image-guided high-

1 Department of Radiology, St. Marianna University School of Medicine

2 Department of Urology, St. Marianna University School of Medicine 
precision methods introduced to mitigate risks of late injury associated with higher doses have been reported to be effective: 3-dimensional conformal radiation therapy (3DCRT) and intensity-modulated radiation therapy $(\text { IMRT })^{899)}$. St. Marianna University School of Medicine Hospital began treating prostate cancer with CT-guided 3DCRT in October 2007. The purpose of this study is to evaluate treatment outcomes of CT-guided 3DCRT for localized prostate cancer.

\section{Materials and Methods}

The subjects in the current study are 139 prostate cancer patients (stage T1c to T3b N0M0) who received CT-guided 3DCRT at our hospital between October 2007 and May 2014 (Table 1). Adenocarcinoma was confirmed for all subjects through histological diagnosis following biopsy. Risk classifications used definitions from the National Comprehensive Cancer Network: low-risk is T1-T2a with PSA of $<10 \mathrm{ng} / \mathrm{mL}$ and Gleason score (GS) of $\leq$ 6; intermediate-risk is T2b-T2c with PSA of 10-20 $\mathrm{ng} / \mathrm{mL}$ and GS of 7; and high-risk is T3 or PSA of $>$ $20 \mathrm{ng} / \mathrm{mL}$ or GS of $8-10$. Patients with T4 cancer or a history of pelvic surgery were excluded. Abdominal $\mathrm{CT}$ and bone scans were used for pre-treatment evaluation. Written informed consent was obtained from all patients prior to treatment, and this study was approved by St. Marianna University School of Medicine Hospital's Institutional Review Board (\#2972).

\section{Radiotherapy}

\section{Treatment planning}

Treatment-planning CT scans were performed at $3 \mathrm{~mm}$ slice thickness with the patients in a supine position and their legs immobilized with heel supports (Engineering System Co., Ltd., Japan). Patients refrained from urinating in the 30 minutes prior to the planning CT examination or radiotherapy. The treatment planning system used was Xio (Computerized Medical Systems, St Louis, MO), while the superposition algorithm was used for calculations. Clinical target volume (CTV) included prostate only for lowrisk patients, and both prostate and proximal seminal vesicles for intermediate-risk and high-risk patients. For T3b patients, the entire seminal vesicle was included. Rectal volume was defined as $2 \mathrm{~cm}$ extending beyond the CTV cranially and caudally. Planning target volume (PTV) was considered equal to CTV. A rectangular rotational beam combined with five fixed beams were used for the $3 \mathrm{DCRT}^{10}$. The rotational beam center and isocenter of fixed beams were the
Table 1. Patient Baseline Clinical and Treatment Characteristics

\begin{tabular}{|c|c|c|}
\hline \multirow[t]{2}{*}{ Age (years) } & \multicolumn{2}{|c|}{ median 74 (range, 56-81) } \\
\hline & $\mathrm{n}$ & $\%$ \\
\hline \multicolumn{3}{|l|}{ T stage } \\
\hline $\mathrm{T} 1 \mathrm{c}$ & 77 & 55 \\
\hline $\mathrm{T} 2$ & 46 & 33 \\
\hline $2 a$ & 10 & \\
\hline $2 b$ & 9 & \\
\hline $2 \mathrm{c}$ & 27 & \\
\hline $\mathrm{T} 3$ & 16 & 12 \\
\hline $3 a$ & 11 & \\
\hline $3 b$ & 5 & \\
\hline \multicolumn{3}{|l|}{ PSA (ng/mL) } \\
\hline$<10$ & 40 & 29 \\
\hline $10-20$ & 36 & 26 \\
\hline$>20$ & 63 & 45 \\
\hline \multicolumn{3}{|l|}{ Gleason Score } \\
\hline$\leqq 6$ & 21 & 15 \\
\hline 7 & 49 & 35 \\
\hline $8-10$ & 69 & 50 \\
\hline \multicolumn{3}{|l|}{ Risk groups } \\
\hline Low & 13 & 9 \\
\hline Intermeiate & 30 & 22 \\
\hline High & 96 & 69 \\
\hline \multicolumn{3}{|l|}{ ADT } \\
\hline Yes & 123 & 88 \\
\hline No & 16 & 12 \\
\hline \multicolumn{3}{|l|}{ ADT rate } \\
\hline Low & $7 / 13$ & 54 \\
\hline Intermediate & $21 / 30$ & 70 \\
\hline High & $95 / 96$ & 99 \\
\hline \multicolumn{3}{|c|}{ ADT duration in high-risk group } \\
\hline short-term $(<24 \mathrm{~m})$ & 34 & 36 \\
\hline long-term $(\geqq 24 \mathrm{~m})$ & 61 & 64 \\
\hline \multicolumn{3}{|l|}{ Riotherapy dose (Gy) } \\
\hline 74 & 45 & 32 \\
\hline 76 & 94 & 68 \\
\hline
\end{tabular}

PSA: Prostate-specific antigen, ADT: Androgen deprivation therapy, m: Month

center of the PTV. Using a beam's-eye view, $1 \mathrm{~cm}$ margins were set to ensure full coverage of the PTV. A multi-leaf collimator was used to help ensure that rectal V70 (percentage of rectal volume receiving 70 Gy or more radiation) was $10 \%$ or lower by adjusting rectal-side margins. Finally, fixed-beam gantry angles and dose weight from each beam were adjusted for homogenous dose distribution over the PTV.

\section{Image-guided radiotherapy (IGRT)}

The linear accelerators used were the Fusion of CT and Linac (FOCAL) unit (Toshiba Medical Systems, Tochigi, Japan) and Elekta Synergy (Elekta, AB, Stockholm, Sweden). For every treatment fraction, the patients were initially prepared using laser marks on their skin, and then repositioned using inroom CT. The FOCAL unit (purchased 2007) used 10 MV x-rays for radiotherapy, while the Elekta Synergy unit (purchased 2013) used 6 MV x-rays follow- 
ing position correction with cone-beam CT and HexaPOD evo.

All patients were treated to their prescribed dose in daily 2 Gy fractions. Total dose was $74 \mathrm{~Gy}$ for the low-risk group and 74 Gy to 76 Gy for the intermediate- and high-risk groups (74 Gy in 32 patients and 76 Gy in 94 patients). Median dose irradiated to $95 \%$ of PTV (PTV D95) was 74.3 Gy (range, 57.8-76.2 Gy), while median rectal V70 was $4.3 \%$ (range, 0 $13.7 \%)$.

\section{Hormone therapy}

Androgen deprivation therapy (ADT) was used at the discretion of the treating physician. Specifically, two patients received bilateral orchiectomy, two patients received oral anti-androgen, and 119 patients received oral anti-androgen and luteinizing hormone-releasing hormone (LH-RH) agonist therapy. One hundred and twenty-three (88\%) out of 139 patients received ADT, and the median duration was 25 months (range, 1-128 months). Among these patients, 23 patients $(19 \%)$ received only neoadjuvant ADT, and the other 100 patients $(81 \%)$ were treated with neoadjuvant ADT, concurrent and adjuvant ADT. ADT treatment rates by risk group were $7 / 13$ low-risk patients (54\%), 21/30 intermediate-risk patients (70\%), and 95/96 high-risk patients (99\%). Median duration between initiation of ADT and start of 3DCRT was 9 months (range, 0-91 months). Longterm ADT (24 months or longer) was administered to low- $(n=3)$, intermediate- $(n=4)$, and high-risk patients $(\mathrm{n}=61)$.

\section{Follow-up}

Patients were examined and PSA measured every 3 to 6 months following radiotherapy completion, with diagnostic imaging performed in patients with suspected biochemical or clinical relapse. Adverse events were evaluated according to National Cancer Institute Common Terminology Criteria for Adverse Events (Ver. 4.0) (Table 2).

\section{Outcomes}

The primary endpoint used in the study was biological relapse-free survival (bRFS). Biochemical relapse was defined according to the RTOG/ASTRO Phoenix Consensus Conference definition (an increase in the PSA concentration of $\geq 2 \mathrm{ng} / \mathrm{mL}$ above the nadir ${ }^{11}$. Secondary endpoints were overall survival (OS), distant metastasis-free survival (DMFS), and cause-specific survival (CSS), with metastasis determined through imaging.

\section{Statistical analysis}

Survival was calculated according to the Kaplan-Meier method, with day 1 as the day of initiation of radiotherapy. Survival rates among groups were compared with the log-rank test. The Cox proportional hazard model was used to assess factors affecting bRFS of high-risk patients; factors were pretreatment PSA $(\leq 20 \mathrm{ng} / \mathrm{mL}$ vs. $>20 \mathrm{ng} / \mathrm{mL})$, GS $(<8$ vs. $8-10)$, T stage (1-2 vs. 3$)$, ADT duration $(<24$ months vs. $\geq 24$ months), and total dose (74 Gy vs. 76 Gy). Factors with $\mathrm{p}<0.5$ under univariate analysis were used for multivariate analysis. Intergroup rectal V70 comparisons used the t-test. Statistical significance level was set at $p<0.05$. Software used for statistical analysis was $R$ version 3.2.1.

\section{Results}

Median follow-up period was 42 months (range, 13-94 months) for surviving patients. PSA relapse was observed in nine patients, all of whom were high-risk and three of whom had distant metastases. Three-year bRFS rates in low-, intermediate-, and high-risk groups were $100 \%, 100 \%$, and $92 \%$, re-

Table 2. National Cancer Institute Common Terminology Criteria for Adverse Events (Version 4.0)

\begin{tabular}{|c|c|c|c|c|c|}
\hline & \multicolumn{5}{|c|}{ Grade } \\
\hline Adverse Event & 1 & 2 & 3 & 4 & 5 \\
\hline Rectal hemorrhage & $\begin{array}{l}\text { Mild; intervention } \\
\text { not indicated }\end{array}$ & $\begin{array}{l}\text { Moderate symptoms; medical } \\
\text { intervention or minor } \\
\text { cauterization indicated }\end{array}$ & $\begin{array}{l}\text { Transfusion, radiologic, } \\
\text { endoscopic, or elective } \\
\text { operative intervention } \\
\text { indicated }\end{array}$ & $\begin{array}{l}\text { Life-threatening } \\
\text { consequences; } \\
\text { urgent intervention } \\
\text { indicated }\end{array}$ & Death \\
\hline $\begin{array}{l}\text { Urinary tract } \\
\text { obstruction }\end{array}$ & $\begin{array}{l}\text { Asymptomatic; } \\
\text { clinical or diagnostic } \\
\text { observations only }\end{array}$ & $\begin{array}{l}\text { Symptomatic but no } \\
\text { hydronephrosis, sepsis, or } \\
\text { renal dysfunction; urethral } \\
\text { dilation, urinary or suprapubic } \\
\text { catheter indicated }\end{array}$ & $\begin{array}{l}\text { Symptomatic and altered } \\
\text { organ function (e.g., } \\
\text { hydronephrosis, or renal } \\
\text { dysfunction); elective } \\
\text { radiologic, endoscopic or } \\
\text { operative intervention } \\
\text { indicated }\end{array}$ & $\begin{array}{l}\text { Life-threatening } \\
\text { consequences; } \\
\text { urgent intervention } \\
\text { indicated }\end{array}$ & Death \\
\hline
\end{tabular}


spectively (Fig. 1), demonstrating significantly worse results for the high-risk group $(\mathrm{p}=0.03)$. Table 3 shows the result of analysis of factors affecting bRFS in high-risk patients. Univariate analysis revealed no significant factors, but in multivariate analysis, ADT of 24 months or longer was an independent prognostic factor (HR 0.23, 95\% CI 0.05-0.96, p = 0.044).

At the time of the analysis, 10 out of 139 patients had died. Of these, two died of prostate cancer, five of other malignant tumors (one each of gastric lymphoma and lung, gastric, pancreas, and bladder cancers), and one each from chronic obstructive pulmonary disease (COPD), renal failure, and pneumonia.

Three-year OS rates in low-, intermediate-, and high-risk groups were $100 \%, 96 \%$, and $95 \%$, respectively $(\mathrm{p}=0.66)($ Fig 2$)$, while 3-year DMFS rates were $100 \%, 100 \%$, and $96 \%$, respectively $(\mathrm{p}=0.23)$ (Fig. 3). Finally, 3-year CSS rates were 100\%, 100\%, and $98 \%$, respectively $(\mathrm{p}=0.31)(\mathbf{F i g} .4)$ in low-, intermediate-, and high-risk groups.
Acute toxicity was observed in one patient with grade 2 urethral stenosis, who completed treatment with 74 Gy. All other patients completed planned radiotherapy. Grade 2 late rectal toxicity was observed in five patients $(3.6 \%)$, with a mean time to rectal bleeding of 8.8 months (range, 7-12 months) following completion of radiotherapy. Mean rectal V70 was $6.2 \%$ (range, $4.2-8.6 \%$ ) for the five patients with rectal toxicity, and $4.6 \%$ (range, $0-13.7 \%$ ) for the 134 patients with no rectal toxicity $(\mathrm{p}=0.16)$. The only instance of late urinary toxicity observed was in one patient $(0.7 \%)$ with grade 2 urethral stenosis. No grade 3 or higher acute or late toxicities were observed.

\section{Discussion}

We studied treatment outcomes from CT-guided high-dose 3DCRT performed at our hospital. Toxicity was within the tolerable range, and results demonstrated safety. Low- and intermediate-risk groups demonstrated 100\% 3-year bRFS; the rate for the

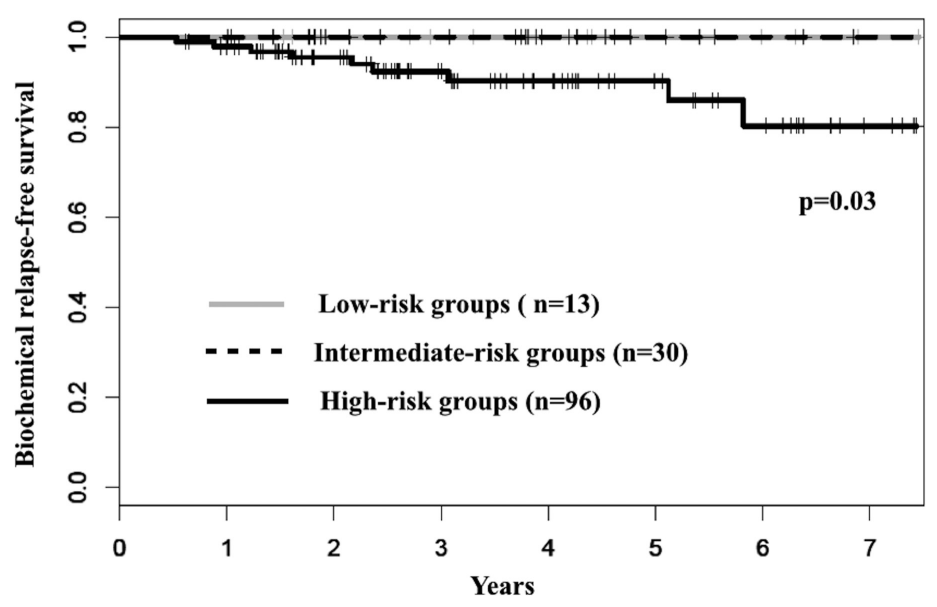

Fig. 1. Biochemical relapse-free survival by risk stratification for 139 men treated for localized prostate cancer with CT-guided 3DCRT.

Table 3. Statistical Analysis of Predictors for the Biochemical Relapse-free Survival of High-risk

Patients

\begin{tabular}{lcccc}
\hline & \multicolumn{2}{c}{ Univariate } & \multicolumn{2}{c}{ Multivariate } \\
\hline \multicolumn{1}{c}{ Variable } & p value & HR $(95 \%$ CI $)$ & p value & HR $(95 \%$ CI $)$ \\
\hline PSA ( $\leqq 20 \mathrm{ng} / \mathrm{mL}$ vs. $>20 \mathrm{ng} / \mathrm{mL})$ & 0.15 & $4.45(0.55-35.62)$ & 0.16 & $4.57(0.52-39.83)$ \\
Gleason Score ( <8 vs. 8-10) & 0.14 & $0.37(0.09-1.41)$ & 0.46 & $0.60(0.15-2.36)$ \\
T stage ( 1-2 vs. 3) & 0.99 & $1.00(0.20-4.99)$ & & \\
ADT durarion (<24m vs. $\geqq 24 \mathrm{~m})$ & 0.06 & $0.27(0.06-1.09)$ & 0.044 & $0.23(0.05-0.96)$ \\
Radiation dose ( 74Gy vs. 76Gy) & 0.65 & $1.46(0.27-7.81)$ & & \\
\hline
\end{tabular}

PSA: Prostate-specific antigen, ADT: Androgen deprivation therapy, m: Month, HR: Hazard ratio, CI: Confidence interval 


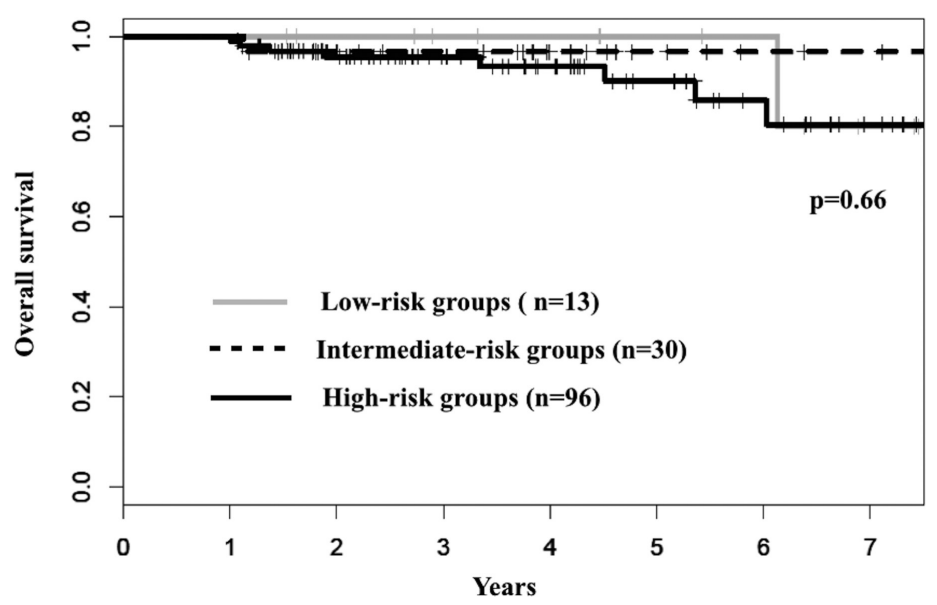

Fig. 2. Overall survival by risk stratification for 139 men treated for localized prostate cancer with CT-guided 3DCRT.

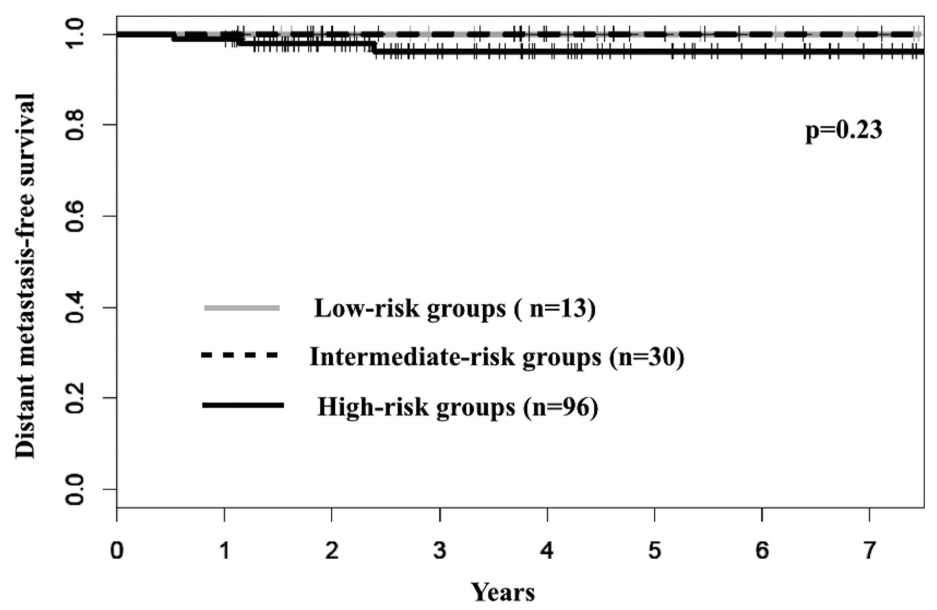

Fig. 3. Distant metastasis-free survival by risk stratification for 139 men treated for localized prostate cancer with CT-guided 3DCRT.

high-risk group was significantly worse at $92 \%$. At other facilities, 3-year bRFS was reported to be 97$100 \%, 95-100 \%$, and $90-92 \%$ in low-, intermediate-, and high-risk patients, respectively. The results from the present study were similar to those reported at other facilities, although the duration of follow-up was shorter (Table 4); possible reasons are shortness of the follow-up period, efficacy of CT-guided highdose 3DCRT, and high rates of ADT with longer treatment periods for high-risk patients. However, drawing concrete conclusions is difficult.

Randomized studies to date have shown the necessity for long-term (24-months) adjuvant ADT with external irradiation for high-risk patients. In contrast, shorter periods of ADT (6 months) are con- sidered effective for intermediate-risk patients, and ADT is considered unnecessary for low-risk patients $^{12-14)}$. However, this data is for doses of $70 \mathrm{~Gy}$ or lower, and the efficacy of adjuvant ADT and optimal treatment periods for intermediate- and high-risk patients receiving 74-80 Gy, which is currently becoming the standard dose, remains unknown. Zapatero et al. ${ }^{15)}$ compared short- (4 -months) and long-term (24 months) ADT combined with 76-82 Gy 3DCRT in intermediate- and high-risk patients in a randomized study; results showed that long-term ADT improved biochemical disease-free survival, metastasis-free survival, and OS. Long-term ADT was particularly effective in high-risk patients. We only studied prognostic factors for high-risk patients, as no low- or in- 


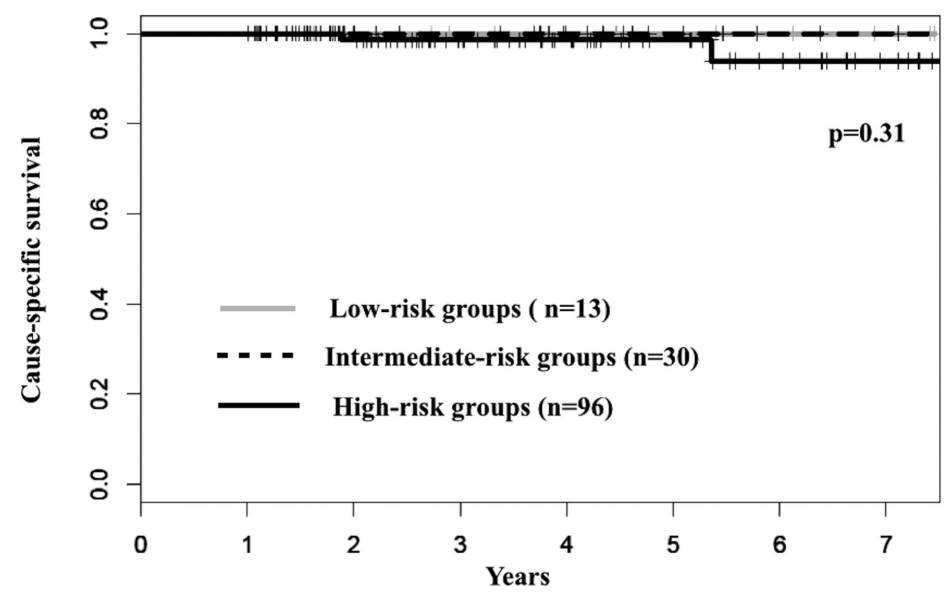

Fig. 4. Cause-specific survival by risk stratification for 139 men treated for localized prostate cancer with CT-guided 3DCRT.

Table 4. Literature Review

\begin{tabular}{|c|c|c|c|c|c|c|c|c|c|c|}
\hline Author & $\begin{array}{c}\text { RT dose } \\
\text { (Gy) }\end{array}$ & Method & Risk group & $\begin{array}{c}\text { ADT rate } \\
(\%)\end{array}$ & $\begin{array}{l}\text { ADT duration } \\
(\mathrm{m})\end{array}$ & \multicolumn{2}{|c|}{$\begin{array}{c}\text { bRFS } \\
(\%)\end{array}$} & $\begin{array}{c}\text { DMFS } \\
(\%) \\
\end{array}$ & $\begin{array}{l}\text { CSS } \\
(\%) \\
\end{array}$ & $\begin{array}{l}\text { OS } \\
(\%) \\
\end{array}$ \\
\hline \multirow{3}{*}{$\begin{array}{c}\text { Martin JM } \\
\text { (8) }\end{array}$} & 79.8 & IG-3DCRT & low & 13.6 & $<6$ & 5-year & 88.4 & - & - & - \\
\hline & & or & intermediate & 11 & $<6$ & & 76.5 & - & - & - \\
\hline & & IG-IMRT & high & 45.9 & $24-36$ & & 77.9 & - & - & - \\
\hline \multirow{3}{*}{$\begin{array}{l}\text { Spratt DE } \\
\text { (18) }\end{array}$} & 86.4 & IMRT & low & 27.5 & 6 & 7-year & 98.8 & 99.4 & 100 & - \\
\hline & & & intermediate & 47.8 & 6 & & 85.6 & 94.1 & 96.7 & - \\
\hline & & & high & 91.3 & $6-24$ & & 67.9 & 82 & 91.9 & - \\
\hline \multirow{2}{*}{$\begin{array}{c}\text { Takeda k } \\
\text { (17) }\end{array}$} & 76 or 80 & IG-IMRT & intermediate & 67 & med 5 (4-32) & 5-year & 100 & 100 & 100 & 100 \\
\hline & & & high & 95 & med $12(2-88)$ & & 82.2 & 95 & 100 & 91.7 \\
\hline \multirow{4}{*}{$\begin{array}{c}\text { Zapatero A } \\
\text { (15) }\end{array}$} & $76-82$ & 3DCRT & intermediate & 100 & short-term (4) & 5-year & 88 & 89 & - & 91 \\
\hline & & & intermediate & & long-tem (24) & & 92 & 94 & - & 94 \\
\hline & & & hioh & 100 & short-term (4) & & 76 & 79 & - & 82 \\
\hline & & & ingil & & long-term (24) & & 88 & 94 & - & 96 \\
\hline \multirow[t]{3}{*}{ Our study } & 74 or 76 & IG-3DCRT & low & 54 & med $21(8-45)$ & 3-year & 100 & 100 & 100 & 100 \\
\hline & & & intermediate & 70 & med $10(1-48)$ & & 100 & 100 & 100 & 96 \\
\hline & & & high & 99 & med $29(2-128)$ & & 92 & 96 & 98 & 95 \\
\hline
\end{tabular}

IG: Image-guided, 3DCRT: 3-dimensional conformal radiotherapy, IMRT: intensity-modulated radiotherapy, ADT: Androgen deprivation therapy, bRFS: biochemical relapse-free survival, DMFS: Distant metastasis-free survival, CSS: Cause-spesific survival, OS: Overall survival, med: Median

termediate-risk patients exhibited biochemical relapses. Multivariate analysis showed that only ADT of 24 months or longer was an independent factor for improving bRFS. Although this study is limited by the small number of patients analyzed and the nature of retrospective studies, results suggest that long-term ADT improves bRFS in the dosage range of 74-76 Gy, as well as in lower doses.

No low- or intermediate-risk patients exhibited distant metastases or died of prostate cancer. Threeyear DMFS and 3-year CSS rates for high-risk patients were $96 \%$ and $98 \%$, respectively. At other facilities, 3-year DMFS was reported to be $100 \%$, 98$100 \%$, and 95-97\% in low-, intermediate-, and high- risk patients, respectively, and 3-year CSS was reported to be $100 \%, 99-100 \%$, and $98-100 \%$, respectively. The results from the present study were similar to those reported at other facilities, although the duration of follow-up was shorter (Table 4). Despite confounding factors, such as the shortness of follow-up period and effects from ADT, this study showed low rates of distant metastases and death from prostate cancer even in high-risk patients with localized prostate cancer following treatment with CT-guided highdose 3DCRT. The key to improving OS is discovering malignant tumors other than prostate cancer early and controlling chronic diseases.

The only acute toxicity observed was in one pa- 
tient with a grade 2 event, which was within permissible levels. The reported incidence of grade 2 or higher late rectal and urinary toxicities due to 66-86.4 Gy external irradiation is $1-9 \%$ and $6.3-21.1 \%$, respectively ${ }^{16-19}$. In our study, the rates of grade 2 late rectal and urinary toxicities were $3.6 \%$ and $0.7 \%$, respectively, while no grade 3 or higher toxicities were observed. Rectal volume exposed to high-dose radiation is a key risk factor for late rectal toxicity, which has been shown to increase significantly at rectal V70 of $>15 \%{ }^{19)}$. Risk factors reported for late urinary toxicity include urinary toxicity during the radiotherapy treatment period, high-dose radiation, and treatment with non-IGRT ${ }^{916)}$. Possible reasons for low incidence of grade 2 or higher late rectal and urinary toxicities in the current study include accurate IGRT, and the relatively low volume of the rectum subject to high-dose radiation (rectal V70 = median $4.3 \%$ ). Currently our hospital is in the process of transitioning from CT-guided 3DCRT for prostate cancer to CT-guided IMRT. Total dose will remain at 76 Gy based on treatment experience to date, but IMRT offers better spatial dose distribution than 3DCRT, so treatment outcomes may improve.

In conclusion, this study examined treatment outcomes of CT-guided high-dose 3DCRT for localized prostate cancer. Adverse events were within permissible levels, indicating the safety of the treatment. Three-year bRFS rates were good, but significantly worse in the high-risk group compared to low-risk and intermediate-risk groups. Long-term ADT (24 -months or longer) influenced bRFS in the high-risk group. Distant metastases and death from prostate cancer were observed in several patients in the highrisk group. Going forward, further follow-up and observation are warranted in order to better evaluate long-term outcomes.

\section{References}

1) Kupelian PA. Comparison of the Efficacy of Local Therapies for Localized Prostate Cancer in the Prostate-Specific Antigen Era: A Large Single-Institution Experience With Radical Prostatectomy and External-Beam Radiotherapy. Journal of Clinical Oncology 2002; 20: 3376-3385.

2) Viani GA, Stefano EJ, Afonso SL. Higher-thanconventional radiation doses in localized prostate cancer treatment: a meta-analysis of randomized, controlled trials. Int J Radiat Oncol Biol Phys 2009; 74: 1405-1418.

3) Kuban DA, Levy LB, Cheung MR, Lee AK,
Choi S, Frank S, Pollack A. Long-term failure patterns and survival in a randomized dose-escalation trial for prostate cancer. Who dies of disease? Int J Radiat Oncol Biol Phys 2011; 79: 1310-1317.

4) Zietman AL, Bae K, Slater JD, Shipley WU, Efstathiou JA, Coen JJ, Bush DA, Lunt M, Spiegel DY, Skowronski R, Jabola BR, Rossi CJ. Randomized trial comparing conventional-dose with high-dose conformal radiation therapy in early-stage adenocarcinoma of the prostate: long-term results from proton radiation oncology group/american college of radiology 95-09. J Clin Oncol 2010; 28: 1106-1111.

5) Dearnaley DP, Jovic G, Syndikus I, Khoo V, Cowan RA, Graham JD, Aird EG, Bottomley D, Huddart RA, Jose CC, Matthews JH, Millar JL, Murphy C, Russell JM, Scrase CD, Parmar MK, Sydes MR. Escalated-dose versus control-dose conformal radiotherapy for prostate cancer: long-term results from the MRC RT01 randomised controlled trial. Lancet Oncol 2014; 15: 464-473.

6) Peeters ST, Heemsbergen WD, Koper PC, van Putten WL, Slot A, Dielwart MF, Bonfrer JM, Incrocci L, Lebesque JV. Dose-response in radiotherapy for localized prostate cancer: results of the Dutch multicenter randomized phase III trial comparing 68 Gy of radiotherapy with $78 \mathrm{~Gy}$. J Clin Oncol 2006; 24: 1990-1996.

7) Beckendorf V, Guerif S, Le Prise E, Cosset JM, Bougnoux A, Chauvet B, Salem N, Chapet O, Bourdain S, Bachaud JM, Maingon P, HannounLevi JM, Malissard L, Simon JM, Pommier P, Hay M, Dubray B, Lagrange JL, Luporsi E, Bey P. 70 Gy versus 80 Gy in localized prostate cancer: 5-year results of GETUG 06 randomized trial. Int J Radiat Oncol Biol Phys 2011; 80: 1056-1063.

8) Martin JM, Bayley A, Bristow R, Chung P, Gospodarowicz M, Menard C, Milosevic M, Rosewall $\mathrm{T}$, Warde PR, Catton CN. Image guided dose escalated prostate radiotherapy: still room to improve. Radiat Oncol 2009; 4: 50.

9) Zelefsky MJ, Kollmeier M, Cox B, Fidaleo A, Sperling D, Pei X, Carver B, Coleman J, Lovelock M, Hunt M. Improved clinical outcomes with high-dose image guided radiotherapy compared with non-IGRT for the treatment of clinically localized prostate cancer. Int J Radiat Oncol Biol Phys 2012; 84: 125-129. 
10) Taira S, Hizume M, Note I, Sugimoto J, Okita R. A template for forward planning in prostate cancer treatment: conformal irradiation with segmental intensity-modulation. Igaku Butsuri 2003; 23: 59-64.

11) Roach M, 3rd, Hanks G, Thames H, Jr., Schellhammer P, Shipley WU, Sokol GH, Sandler H. Defining biochemical failure following radiotherapy with or without hormonal therapy in men with clinically localized prostate cancer: recommendations of the RTOG-ASTRO Phoenix Consensus Conference. Int J Radiat Oncol Biol Phys 2006; 65: 965-974.

12) Pilepich MV, Winter K, John MJ, Mesic JB, Sause W, Rubin P, Lawton C, Machtay M, Grignon D. Phase III radiation therapy oncology group (RTOG) trial 86-10 of androgen deprivation adjuvant to definitive radiotherapy in locally advanced carcinoma of the prostate. Int $\mathrm{J}$ Radiat Oncol Biol Phys 2001; 50: 1243-1252.

13) Hanks GE, Pajak TF, Porter A, Grignon D, Brereton H, Venkatesan V, Horwitz EM, Lawton C, Rosenthal SA, Sandler HM, Shipley WU. Phase III trial of long-term adjuvant androgen deprivation after neoadjuvant hormonal cytoreduction and radiotherapy in locally advanced carcinoma of the prostate: the Radiation Therapy Oncology Group Protocol 92-02. J Clin Oncol 2003; 21: 3972-3978.

14) D'Amico AV, Manola J, Loffredo M, Renshaw AA, DellaCroce A, Kantoff PW. 6-month androgen suppression plus radiation therapy vs radiation therapy alone for patients with clinically localized prostate cancer: a randomized controlled trial. JAMA 2004; 292: 821-827.

15) Zapatero A, Guerrero A, Maldonado $X$, Alvarez A, Gonzalez San Segundo C, Cabeza Rodriguez MA, Macias V, Pedro Olive A, Casas F, Boladeras A, de Vidales CM, Vazquez de la Torre ML,
Villa S, Perez de la Haza A, Calvo FA. Highdose radiotherapy with short-term or long-term androgen deprivation in localised prostate cancer (DART01/05 GICOR): a randomised, controlled, phase 3 trial. Lancet Oncol 2015; 16: 320-327.

16) Zelefsky MJ, Levin EJ, Hunt M, Yamada Y, Shippy AM, Jackson A, Amols HI. Incidence of late rectal and urinary toxicities after three-dimensional conformal radiotherapy and intensitymodulated radiotherapy for localized prostate cancer. Int J Radiat Oncol Biol Phys 2008; 70: 1124-1129.

17) Takeda K, Takai $Y$, Narazaki $K$, Mitsuya M, Umezawa R, Kadoya N, Fujita Y, Sugawara T, Kubozono M, Shimizu E, Abe K, Shirata Y, Ishikawa Y, Yamamoto T, Kozumi M, Dobashi S, Matsushita H, Chida K, Ishidoya S, Arai Y, Jingu K, Yamada S. Treatment outcome of highdose image-guided intensity-modulated radiotherapy using intra-prostate fiducial markers for localized prostate cancer at a single institute in Japan. Radiat Oncol 2012; 7: 105.

18) Spratt DE, Pei X, Yamada J, Kollmeier MA, Cox B, Zelefsky MJ. Long-term survival and toxicity in patients treated with high-dose intensity modulated radiation therapy for localized prostate cancer. Int J Radiat Oncol Biol Phys 2013; 85: 686-692.

19) Michalski JM, Yan Y, Watkins-Bruner D, Bosch WR, Winter K, Galvin JM, Bahary JP, Morton GC, Parliament MB, Sandler HM. Preliminary toxicity analysis of 3-dimensional conformal radiation therapy versus intensity modulated radiation therapy on the high-dose arm of the Radiation Therapy Oncology Group 0126 prostate cancer trial. Int J Radiat Oncol Biol Phys 2013; 87: 932-938. 